\title{
OTIMIZAÇÃO EXPERIMENTAL DO RECOBRIMENTO DE PARTÍCULAS DE UREIA EM LEITO DE JORRO
}

\author{
T. P. DA COSTA ${ }^{1}$, B. DE ZORZI ${ }^{1}$, F. B. D. NORA ${ }^{1}$, G. F. WESTPHALEN ${ }^{1}$, G. S. ROSA ${ }^{1 *}$ \\ ${ }^{1}$ Universidade Federal do Pampa, Curso de Engenharia Química \\ *e-mail: gabrielarosa@ unipampa.edu.br
}

\begin{abstract}
RESUMO
O nitrogênio ocupa posição de destaque dentre os elementos essenciais ao desenvolvimento das espécies vegetais, fornecido geralmente através da aplicação da ureia. No entanto, o nitrogênio presente na ureia apresenta alta susceptibilidade à volatilização, que pode chegar a $80 \%$ em algumas condições. Para que haja a minimização destas perdas, o recobrimento da ureia é uma estratégia que vem sendo difundida atualmente. Este trabalho teve como objetivo estudar o processo de recobrimento em leito de jorro utilizando uma suspensão polimérica que proporcione uma liberação lenta do nitrogênio presente na ureia. Foi elaborado um planejamento experimental fatorial do tipo estrela, cujas variáveis estudadas foram: vazão da suspensão de recobrimento e temperatura de entrada do ar; e as respostas avaliadas foram a eficiência do recobrimento, o crescimento da partícula e a redução da volatilidade do nitrogênio presente na ureia. A estimativa das condições ótimas para as variáveis de resposta definidas no planejamento experimental foi realizada com base na técnica de otimização simultânea denominada função desejabilidade. As condições otimizadas foram $80,6^{\circ} \mathrm{C}$ de temperatura do ar de entrada e $16,2 \mathrm{~mL} / \mathrm{min}$ de vazão da suspensão de recobrimento, que possibilitam obter uma eficiência igual a $48,1 \%$, um crescimento de partícula de $4,4 \%$ e uma redução na volatilidade de $49,3 \%$.
\end{abstract}

\section{INTRODUÇÃO}

Entre os diversos nutrientes necessários ao bom desenvolvimento das culturas agrícolas, o nitrogênio destaca-se como elemento fundamental e indispensável, atuando na manutenção e aumento da produtividade. $\mathrm{O}$ fertilizante de maior concentração de nitrogênio utilizado no Brasil é a ureia. Entretanto, este fertilizante possui alta susceptibilidade à volatilização do nitrogênio, fazendo com que a eficiência seja prejudicada. Foram observadas perdas de até $80 \%$ do total do fertilizante aplicado no solo em determinadas condições (DUARTE, 2007).

Segundo Cantarella (2007), muitas estratégias estão sendo desenvolvidas com o objetivo de minimizar as perdas de nitrogênio. Dentre estas estratégias, está incluído o uso da ureia recoberta, também conhecidos como fertilizantes de libertação lenta ou controlada.

Os fertilizantes de liberação controlada são produtos com propriedades de dissolução mais lenta no solo, obtidos através do recobrimento do fertilizante com materiais pouco permeáveis. A finalidade do encapsulamento é formar uma camada protetora contra os agentes causadores da perda de nutrientes e que esta proteção não interfira na disponibilização do nutriente à planta (VITTI; REIRINCHS, 2007).

Para fabricação deste tipo de fertilizante, um dos principais métodos é recobri-lo com um material pouco solúvel em água, 
semipermeável ou impermeável com microporos. Isto controla a entrada e saída da água e, portanto, a taxa de dissolução dos nutrientes contidos dentro da cápsula, sincronizando a liberação de nutrientes de acordo com as necessidades das plantas (BORSARI, 2013).

Os equipamentos mais utilizados para a operação de recobrimento são o tambor rotativo e o leito de jorro, nas suas diferentes conformações (MATHUR; EPSTEIN, 1974). $\mathrm{O}$ leito de jorro é um equipamento que devido à boa movimentação das partículas e ao ótimo contato fluido-partículas, tem sido tema de diversos trabalhos de recobrimento (DONIDA, 2000; TUNALA, 2005; ROSA 2010).

No leito de jorro, o recobrimento é feito pela movimentação das partículas por uma corrente de gás ascendente sobre as quais é pulverizada uma suspensão de recobrimento utilizando um bico atomizador. Neste caso, o recobrimento é caracterizado pelo crescimento que ocorre em torno da partícula, na qual a suspensão atomizada colide e adere-se à superfície num processo simultâneo de umedecimento e secagem (SILVA, 2003).

Segundo Rezende (2007), o desempenho de um equipamento de recobrimento é avaliado com base em três critérios: qualidade do produto, eficiência do processo e tempo de processamento. Deste modo, a operação de recobrimento é considerada ótima quando o produto obtido apresenta a qualidade pretendida, apresentando um mínimo de aglomerados de partículas e liberação do material ativo dentro das especificações desejadas.

Neste sentido, este trabalho teve como objetivo estudar o processo de recobrimento em leito de jorro utilizando uma função desejabilidade para a estimativa das condições ótimas para o processo.

\section{MATERIAIS E MÉTODOS}

O estudo foi conduzido no laboratório de Fenômenos de Transporte da Universidade Federal do Pampa (Unipampa) em Bagé, Rio Grande do Sul.

\subsection{Materiais}

A ureia utilizada no processo de recobrimento foi a ureia comercial em grânulos de lote único, concedida por agricultor da cidade de Bagé. O diâmetro de Sauter foi obtido por ensaio de peneiramento utilizando peneiras Tyler e é igual a 2,83 $\mathrm{mm}$. A massa específica real, $1,3405 \mathrm{~g} / \mathrm{cm}^{3}$, foi determinada por picnometria gasosa utilizando gás Helio (Ultrapyc 1200e Quantachrome). Com estes valores e a massa específica do ar, utilizando o diagrama de Geldart, as partículas de ureia foram classificadas como grupo D (jorrável), o que justifica a escolha do leito de jorro para o processo de recobrimento.

\subsection{Preparo da suspensão de recobrimento}

Para o recobrimento da ureia foi utilizada uma suspensão aquosa de natureza polimérica capaz de fornecer uma superfície de recobrimento uniforme e de baixo valor comercial.

A formulação das suspensões aquosas poliméricas testadas tem como base os estudos anteriores realizados por Donida (2000) e Rosa (2010) para o recobrimento de ureia em leito de jorro, objetivando substituir o polímero Eudragit $^{\circledR}$ por outro polímero que possui menor custo.

A formulação da suspensão aquosa escolhida apresenta $0,5 \%$ de gelatina, $0,5 \%$ de amido, $2 \%$ do polímero comercial ColorSeed ${ }^{\circledR}$, $3 \%$ de plastificante (glicerol), $9 \%$ de talco e $85 \%$ de água.

No procedimento de preparo das suspensões, primeiramente foram pesados os insumos nas suas devidas proporções em balança analítica. Posteriormente, foram agitados a $800 \mathrm{rpm}$ em agitador mecânico. 
Após a completa solubilização do talco, foram adicionados à suspensão o plastificante (glicerol), o pigmento (proporcionado pelo ColorSeed $^{\circledR}$ ) e por último os polímeros (gelatina e amido), permanecendo sob agitação por $30 \mathrm{~min}$.

A suspensão de recobrimento foi caracterizada quanto à concentração de sólidos, massa específica e $\mathrm{pH}$. A concentração foi determinada pelo método de estufa a $105^{\circ} \mathrm{C}$ durante $24 \mathrm{~h}$ e apresentou $(13,54 \pm 0,84) \%$ de sólidos. A massa específica foi obtida por picnometria líquida, sendo esta de 1,057 \pm $0,002 \mathrm{~g} / \mathrm{cm}^{3}$ a $25^{\circ} \mathrm{C}$. O pH foi obtido através de medidor de $\mathrm{pH}$ (Metrohm Swisamade), cujo valor é igual a 7,77 na mesma temperatura.

\subsection{Sistema experimental}

O sistema experimental utilizado nos ensaios de recobrimento pode ser visto na Figura 1.

Figura 1 - Leito de jorro utilizado nos ensaios.

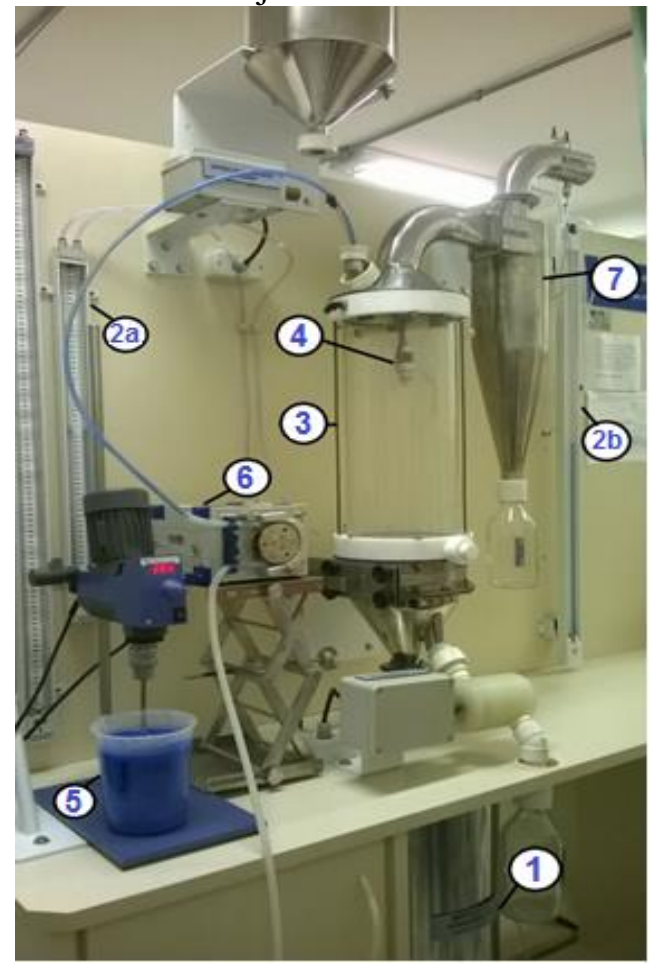

Fonte: Autor (2015).

No sistema observado, o ar de jorro foi alimentado por um compressor centrífugo da marca ARTEK com potência de 7,5 HP e vazão máxima de $6,2 \mathrm{~m}^{3} / \mathrm{min}$. A vazão foi ajustada no painel de controle e medida através de uma placa de orifício (orifício de $30 \mathrm{~mm}$ de diâmetro), onde está acoplado um manômetro de tubo em $\mathrm{U}(2 \mathrm{~b})$. $\mathrm{O}$ ar atravessa um conjunto de resistências (1), onde foi aquecido. As temperaturas de entrada do ar, de saída do cilindro e de saída do ciclone (bulbo seco e úmido) foram acompanhadas por indicadores de temperatura do painel de controle. A queda de pressão no leito foi indicada por um manômetro de tubo em U (2a). O leito de jorro (3) é construído em vidro, com $20 \mathrm{~cm}$ de diâmetro e $50 \mathrm{~cm}$ de altura e a base cônica do leito tem ângulo incluso de $60^{\circ}$, altura de 15 $\mathrm{cm}$ e diâmetro de entrada do ar de $5 \mathrm{~cm}$. O bico atomizador (4), de duplo fluido, encontra-se no interior do cilindro recebendo ar da linha de ar comprimido, fornecido através de um compressor da marca BRAVO com potência de $5 \mathrm{HP}$ e suspensão de recobrimento (5) por meio de uma bomba peristáltica (6) da marca MARCONI modelo MA 2400/400. Um ciclone tipo Lapple (7) está conectado na parte superior do leito de jorro para coletar particulados arrastados pelo ar.

Os experimentos de recobrimento consistiram em abastecer o leito de jorro com a carga de ureia de $500 \mathrm{~g}$, previamente escolhida pelos testes fluidodinâmicos e verificada em testes preliminares de recobrimento. A velocidade do ar de entrada foi fixada em $20 \%$ acima da velocidade de jorro mínimo e foi ajustada no painel de controle. Quando a temperatura de entrada do ar atingiu o valor desejado, deu-se início à alimentação da suspensão de recobrimento na vazão de suspensão estabelecida e ao ar de atomização através do compressor na pressão de atomização fixada em $0,5 \mathrm{kgf} / \mathrm{cm}^{2}$.

Com base na literatura de Rosa (2010), o tempo de atomização da suspensão foi fixado em 20 min para todos os experimentos. Após o ensaio de recobrimento a alimentação da suspensão e o aquecimento do sistema foram 
interrompidos, sendo que as partículas continuaram jorrando por mais 5 min para diminuir a umidade e, então, foram retiradas do leito.

Foi elaborado um planejamento experimental fatorial composto central rotacional (DCCR) do tipo estrela a fim de analisar a influência das condições operacionais sobre a eficiência do processo de recobrimento, crescimento da partícula e a redução da volatilidade do nitrogênio presente na ureia. As variáveis independentes foram: temperatura do ar de $\left(T_{a r}\right)$ e vazão da suspensão de recobrimento $\left(W_{s}\right)$. Essas variáveis foram escolhidas com base na literatura de Adeodato (2003), Tunala (2005) e Rosa (2010).

A codificação dos níveis das variáveis escolhidas estão apresentadas na Tabela 1.

Tabela 1 - Variáveis e níveis utilizados no planejamento experimental fatorial.

\begin{tabular}{cccccc}
\hline Variáveis & \multicolumn{5}{c}{ Níveis } \\
\cline { 2 - 6 } independentes & $-1,41$ & -1 & 0 & 1 & $+1,41$ \\
\hline $\operatorname{Tar}\left({ }^{\circ} \mathrm{C}\right)$ & 60,9 & 65 & 75 & 85 & 89,1 \\
$W_{s}(\mathrm{~mL} / \mathrm{min})$ & 7,8 & 9 & 12 & 15 & 16,2 \\
\hline
\end{tabular}

Os ensaios de recobrimento foram realizados de modo aleatório. Foram feitas 3 repetições no ponto central a fim de fornecer uma medida de erro puro, totalizando 11 ensaios de recobrimento.

A análise estatística dos resultados obtidos foi realizada com base em uma análise de variância (ANOVA) obtida utilizando um software Statistica 7 com o objetivo de verificar se os modelos matemáticos gerados poderiam ser usados para prever as respostas e as influências.

\subsection{Análise do produto obtido}

A eficiência do processo foi calculada utilizando a Equação 1.

$\eta=\frac{m_{f}-m_{0}}{W_{s} \rho_{s} t c_{s}}$
O crescimento da partícula é definido como a razão entre a massa do filme formado durante o recobrimento e a massa original da partícula (ADEODATO, 2003), sendo calculado a partir da Equação 2.

$\delta_{\text {exp }}=\frac{m_{f}-m_{0}}{m_{0}}$

O nitrogênio volatilizado foi quantificado na forma de amônia pelo método direto com sistema de captação estático (DUARTE, 2007). A câmara de volatilização consistiu em um frasco de plástico cilíndrico dotado de tampa. Nos frascos foram colocados $100 \mathrm{~g}$ de terra, onde a ureia foi distribuída na superfície desta, em quantidade equivalente a $100 \mathrm{~kg} \mathrm{~N} /$ hectare, de acordo com o método descrito por Vuolo (2006). Para captar a amônia volatilizada colocou-se um disco de papel filtro em posição horizontal acima da terra, tratado com $1 \mathrm{~mL}$ de $\mathrm{H}_{2} \mathrm{SO}_{4}$ de concentração de $0,5 \mathrm{~mol} / \mathrm{L}$

$\mathrm{O}$ ácido remanescente no coletor foi titulado com solução padronizada de $\mathrm{NaOH}$ $0,02 \mathrm{~mol} / \mathrm{L}$. A análise foi realizada em estufa incubadora com temperatura controlada de $25^{\circ} \mathrm{C}$, por um período de 14 dias, sendo que os coletores foram trocados no primeiro, terceiro, sétimo e décimo quarto dias. A quantidade de nitrogênio volatilizada sob a forma de $\mathrm{NH}_{3} \mathrm{em}$ cada período foi calculada pela Equação 3.

$$
m g \mathrm{NH}_{3 \text { volatilizado }}=\left(V^{\prime}-V^{*}\right) \cdot 0,28
$$

\subsection{Otimização das Variáveis Independentes}

A estimativa das condições ótimas para o recobrimento das partículas de ureia em leito de jorro foi realizada com base nos modelos estatísticos propostos e com o auxílio da técnica de otimização simultânea denominada "Função Desejabilidade" conforme descrito em Akhnazarova e Kafarov (1982) e Barros Neto, Scarminio e Bruns (2007).

A técnica de otimização simultânea é baseada na transformação de uma função 
desejabilidade para cada variável de resposta, com valores descritos entre 0 e 1 , onde 0 representa um valor completamente indesejado e a resposta transformada em 1 o valor mais desejável.

Utiliza-se $A$ como o valor alvo ótimo, situado em algum ponto dentro da faixa de aceitação, cujos limites inferior e superior são representados por $L I$ e $L S$, respectivamente. A função desejabilidade da resposta é definida pelas Equações 4 a 6 .

$d=\left(\frac{\hat{y}-L I}{A-L I}\right)^{S}$, para $L I \leq \hat{y} \leq A ;$

$d=\left(\frac{\hat{y}-L S}{A-L S}\right)^{\tau}, \operatorname{para} A \leq \hat{y} \leq L S ;$

$d=0$, para $\hat{y}$ fora do intervalo $(L I, L S) ;(6)$

onde $\hat{y}$ é a resposta e s e $\tau$ são coeficientes.

À medida que o valor de $\hat{y}$ se afasta do alvo A, o valor da desejabilidade diminui, tornando-se zero quando um dos limites da faixa de aceitação for alcançado (BARROS NETO; SCARMINIO; BRUNS, 2007).

Uma vez que as funções de desejabilidade tenham sido especificadas para todas as respostas, essas foram combinadas em uma desejabilidade global, dada pela média geométrica das i desejabilidades individuais, vista na Equação 7.

$D=\sqrt[i]{d_{1} d_{2} \ldots d_{i}}$

\section{RESULTADOS E DISCUSSÃO}

A Tabela 2 apresenta resultados de eficiência, crescimento da partícula e redução da volatilidade obtidos para os ensaios realizados.
Tabela 2 - Eficiência do recobrimento e crescimento da partícula.

\begin{tabular}{cccccc}
\hline Ensaio & $\mathrm{T}_{\mathrm{ar}}$ & $\mathrm{W}_{\mathrm{s}}$ & $\begin{array}{c}\text { Eficiência } \\
(\%)\end{array}$ & $\begin{array}{c}\text { Crescimento } \\
(\%)\end{array}$ & $\begin{array}{c}\text { Redução da } \\
\text { volatilidade } \\
(\%)\end{array}$ \\
\hline 1 & -1 & -1 & 17,26 & 0,85 & 17,80 \\
2 & -1 & +1 & 42,05 & 3,46 & 40,95 \\
3 & +1 & -1 & 33,84 & 1,94 & 40,66 \\
4 & +1 & +1 & 42,33 & 3,48 & 50,97 \\
5 & $-1,41$ & 0 & 31,42 & 2,06 & 29,47 \\
6 & $+1,41$ & 0 & 46,87 & 3,26 & 36,67 \\
7 & 0 & $-1,41$ & 38,01 & 1,89 & 11,77 \\
8 & 0 & $+1,41$ & 46,98 & 4,41 & 49,81 \\
$9(\mathrm{C})$ & 0 & 0 & 23,78 & 1,60 & 38,33 \\
$10(\mathrm{C})$ & 0 & 0 & 25,59 & 1,72 & 37,35 \\
$11(\mathrm{C})$ & 0 & 0 & 26,82 & 1,80 & 36,77 \\
\hline
\end{tabular}

Observando a Tabela 2 pode-se verificar que para um tempo fixo de processo de $20 \mathrm{~min}$, a faixa obtida para o rendimento do recobrimento foi de 17 a $47 \%$.

Para o crescimento da partícula, foram obtidos valores entre 0,8 e 4,41\%. De acordo com Donida (2000), recobrimentos do tipo filmes poliméricos são caracterizados por resultar em um crescimento da partícula de 2 a $5 \%$. De acordo com a Tabela 2 alguns resultados estão abaixo do esperado para um recobrimento tipo filme. Entretanto, tempos maiores de recobrimento poderiam aumentar a espessura do filme de recobrimento formado.

Verificou-se que o filme de recobrimento proporcionou uma diminuição das perdas por volatilização de nitrogênio para todas as condições do planejamento experimental, em que o percentual de redução da volatilidade ficou entre de 11 e $51 \%$, sendo estes resultados satisfatórios.

Foi verificada uma boa reprodutibilidade do processo de recobrimento através dos resultados obtidos pelos experimentos 9 a 11, que correspondem aos pontos centrais.

Com base na análise estatística dos resultados obtidos, verificou-se a influência das condições operacionais do processo (variáveis independentes) nas respostas. As 
Figuras 2 a 4 apresentam a influência dos efeitos principais e de suas interações através do diagrama de Pareto, para um limite de confiança de $95 \%(p \leq 0,05)$.

Figura 2 - Diagrama de Pareto dos efeitos padronizados para a eficiência do processo.

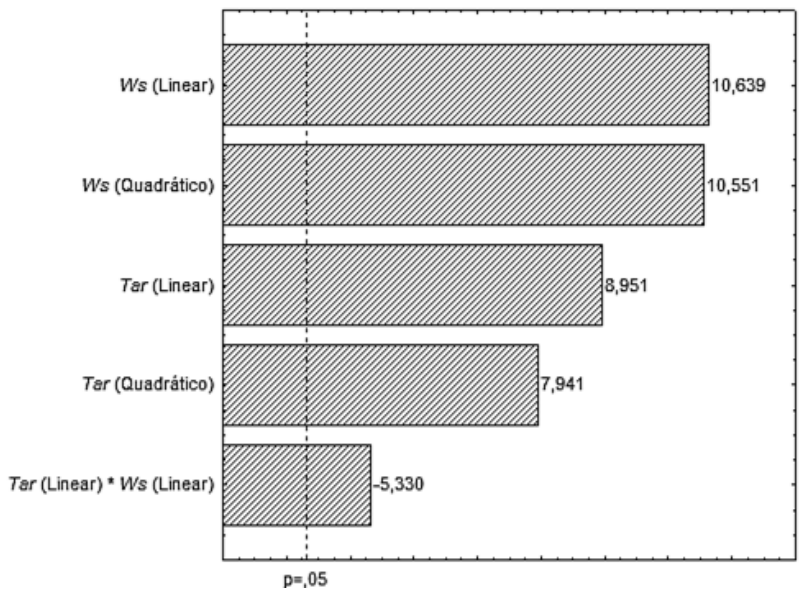

Fonte: Autor (2015).

Figura 3 - Diagrama de Pareto dos efeitos padronizados para o crescimento da partícula.

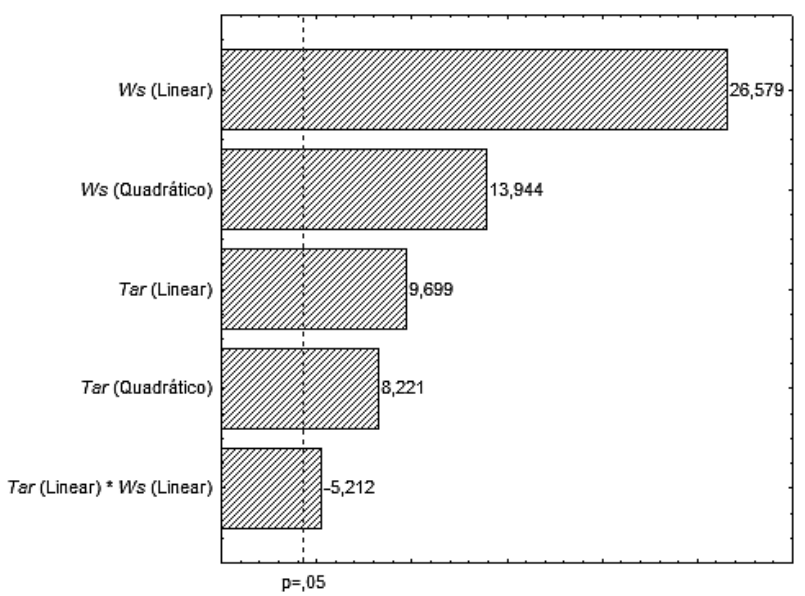

Fonte: Autor (2015).
Figura 4 - Diagrama de Pareto dos efeitos padronizados para a redução da volatilidade.

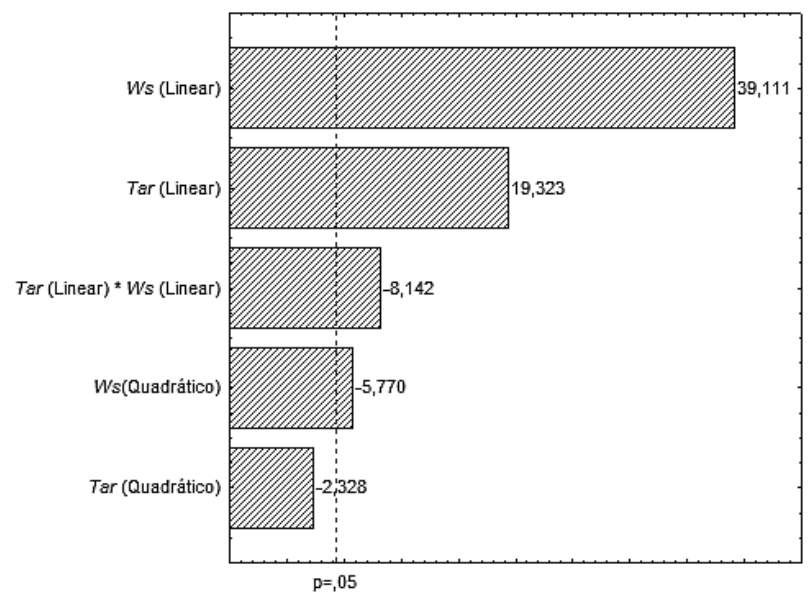

Fonte: Autor (2015).

Observa-se pelas Figuras 2 a 4 que o efeito da vazão da suspensão foi o mais pronunciado, seguido pelo efeito da temperatura de entrada do ar. Ambos os efeitos tiveram influência positiva sobre a resposta, indicando que quaisquer das respostas aumentam de acordo com o aumento de um desses parâmetros.

A estimativa das condições ótimas para as variáveis de resposta definidas no planejamento experimental foi realizada com base na função desejabilidade. A Tabela 3 apresenta as especificações dos valores numéricos para o limite inferior, valor médio e limite superior requeridos pelo software como entrada para a otimização do processo de recobrimento realizado.

Tabela 3 - Parâmetros utilizados na otimização simultânea das respostas.

\begin{tabular}{cccccc}
\hline Resposta & $L I$ & $M$ & $L S$ & $s$ & $\tau$ \\
\hline Eficiência do & 17,25 & 32,12 & 46,97 & 10 & 10 \\
processo (\%) & $(0)$ & $(0)$ & $(1)$ & & \\
& & & & & \\
Crescimento da & 0,84 & 2,63 & 4,41 & 5 & 5 \\
partícula (\%) & $(0)$ & $(1)$ & $(1)$ & & \\
Redução da & 11,77 & 31,37 & 50,97 & 10 & 1 \\
volatilidade (\%) & $(0)$ & $(0,5)$ & $(1)$ & & \\
\hline
\end{tabular}


Os valores entre parênteses são as desejabilidades. Para a eficiência do processo foram consideradas inaceitáveis as respostas abaixo de $32,12 \%$. Como o objetivo era maximizar esta propriedade, o limite superior foi considerado desejável. A taxa de variação da desejabilidade com a resposta estimada pelo modelo é definida pelos valores dos expoentes $s$ e $\tau$. A escolha depende da prioridade ou da importância relativa que é atribuída a cada resposta (BARROS NETO; SCARMINIO; BRUNS, 2007).

Para a resposta eficiência do processo, os valores altos dos expoentes $s$ e $\tau$ fazem com que a desejabilidade seja muito pequena se a resposta não estiver muito próxima do valor alvo (46,97\%).

Para o crescimento da partícula são aceitos valores acima de $0,84 \%$, mas $\mathrm{o}$ desejável é que eles fiquem acima de 2,63\%.
Já a redução da volatilidade é considerada insatisfatória abaixo de 11,77\%, aceitáveis próximos do ponto médio e satisfatórios próximas do limite superior. $\mathrm{O}$ alto valor escolhido $s$ frente ao baixo valor de $\tau$ faz com que a desejabilidade diminua rapidamente, tornando-se muito baixa a menos que a resposta esteja muito perto do alvo e neste caso é mais aceitável que o valor da resposta fique acima do alvo do que abaixo dele.

A Figura 5 mostra os resultados do algoritmo de otimização. Foi utilizada uma grade de 20 pontos em cada um dos dois fatores, o que significa que os valores das respostas e suas correspondentes desejabilidades foram calculadas em 400 combinações de níveis dos fatores. Todas as respostas foram ajustadas com modelos quadráticos completos.

Figura 5 - Perfil dos valores preditos e desejabilidade para a eficiência, crescimento e redução da volatilidade.
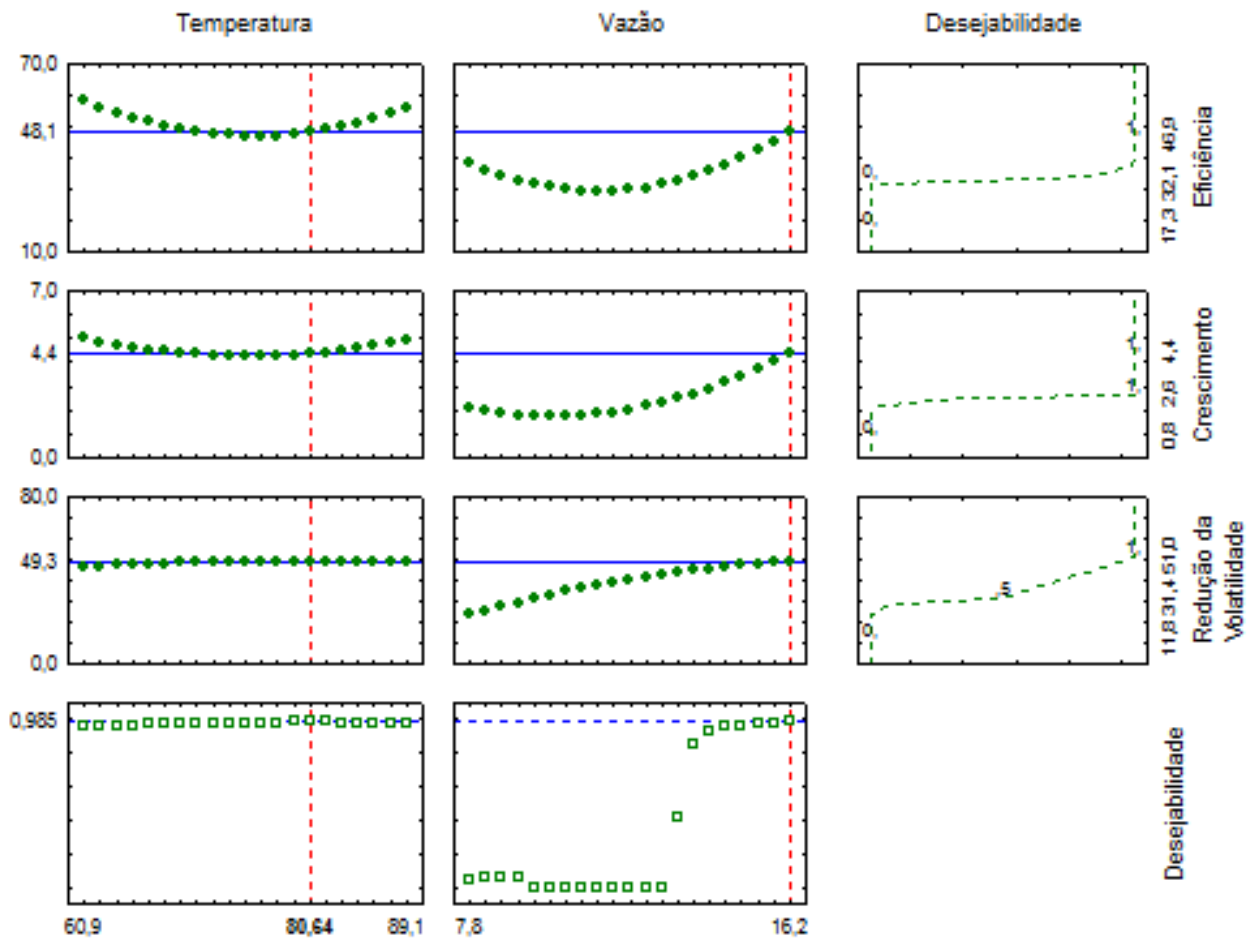

Fonte: Autor (2015). 
Os três gráficos da última coluna mostram os perfis das desejabilidades das respostas, definidos de acordo com os valores escolhidos para os limites e os expoentes da Tabela 3. Para a eficiência do processo há um patamar de desejabilidade 0 abaixo de $32,1 \%$ e para o crescimento da partícula um patamar com desejabilidades 1 acima de 2,6\%. A desejabilidade esperada para a redução da volatilidade apresenta perfil crescente de acordo com o aumento dessa propriedade.

As curvas mostram como as respostas variam com cada fator, mantidos fixos os níveis dos outros fatores nos valores especificados. No terceiro gráfico da primeira coluna, por exemplo, pode-se observar que a redução da volatilidade praticamente não é afetada pela variação da temperatura. $\mathrm{O}$ fator determinante para a obtenção do ponto ótimo neste caso é a vazão da suspensão de recobrimento, que apresenta as inclinações mais pronunciadas. $\mathrm{O}$ gráfico da desejabilidade em função da temperatura (quarta linha e primeira coluna) mostra que este fator pode variar em uma faixa razoável sem causar alterações significativas sobre o valor de $D$. Por outro lado, qualquer alteração na vazão da suspensão provocará uma queda brusca na desejabilidade. Este fator, portanto, deverá ser mantido sob controle mais rigoroso, visto que possui maior influência sobre as respostas.

As linhas tracejadas verticais indicam as condições de máxima desejabilidade global, que para este conjunto de ensaios de recobrimento foi 0,985 , como mostra a última linha de gráfico (linha tracejada azul). Ela foi obtida em $T_{a r}=80,64^{\circ} \mathrm{C}$ e $W_{s}=16,2 \mathrm{~mL} / \mathrm{min}$ (linha tracejada vermelha). Nessas condições será possível obter uma eficiência igual a $48,1 \%$, um crescimento de $4,4 \%$ e uma redução na volatilidade de 49,3\%, como mostram os valores assinalados nos respectivos eixos (linha contínua azul).

A Figura 6 apresenta a superfície e curvas de contorno da função desejabilidade e as combinações das duas variáveis experimentais investigadas.

Figura 6 - Superfície de resposta da função desejabilidade global $(D)$.

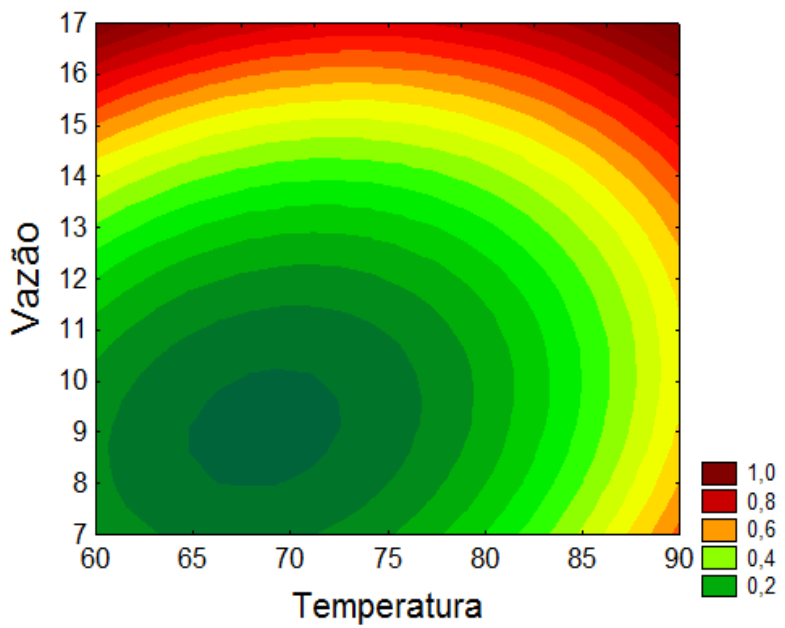

Fonte: Autor (2015).

Observa-se que foi alcançada uma região de máximo, representado pela cor em vermelho, correspondente aos valores ótimos para $D$. Essa região foi observada principalmente em elevadas vazões de suspensão de recobrimento.

\section{CONCLUSÃO}

Através do planejamento experimental fatorial do tipo composto central rotacional foi possível verificar que as variáveis operacionais (temperatura do ar e vazão da suspensão) influenciaram a eficiência do processo de recobrimento, o crescimento das partículas e a redução da volatilidade, para um nível de confiança de $95 \%$.

A faixa obtida para a eficiência do recobrimento foi de 17 a $47 \%$, enquanto o crescimento das partículas variou entre $0,8 \mathrm{e}$ $4,41 \%$. Através das análises da volatilidade pode-se afirmar que o filme de recobrimento proporcionou uma diminuição das perdas por volatilização de nitrogênio para todas as condições do planejamento experimental, em 
que o percentual de redução da volatilidade ficou entre de 11 e $51 \%$.

A estimativa das condições ótimas, para as variáveis de resposta definidas no planejamento experimental, realizada com base na técnica de otimização simultânea denominada função desejabilidade, apresentou como condições otimizadas $\quad 80,6^{\circ} \mathrm{C}$ de temperatura do ar de entrada e $16,2 \mathrm{~mL} / \mathrm{min}$ de vazão da suspensão de recobrimento. Nessas condições é possível obter uma eficiência de $48,1 \%$, um crescimento de partícula de $4,4 \%$ e uma redução na volatilidade de $49,3 \%$.

\section{NOMENCLATURA}

\begin{tabular}{cc}
$A$ & valor alvo \\
$c_{S}$ & concentração de sólidos \\
$d_{i}$ & desejabilidade individual \\
$D$ & desejabilidade global \\
$\delta_{\text {exp }}$ & crescimento da partícula \\
$L I$ & limite inferior \\
$L S$ & limite superior \\
$m_{f}$ & massa final em base seca \\
$m_{0}$ & massa inicial em base seca \\
$M$ & valor médio \\
$\eta$ & eficiência do processo \\
$\rho_{s}$ & massa específica da suspensão \\
$s$ & coeficiente \\
$t$ & tempo \\
$\tau$ & coeficiente \\
$T_{a r}$ & temperatura do ar \\
$V^{\prime}$ & volume de NaOH gasto na prova \\
\multicolumn{3}{c}{ em branco } \\
$V^{*}$ & volume de NaoH gasto na \\
\multicolumn{3}{l}{ titulação } \\
$W_{s}$ & vazão da suspensão \\
$\hat{y}$ & resposta predita
\end{tabular}

\section{REFERÊNCIAS}

\section{ADEODATO, M. G. Análise da} Fluidodinâmica de Leito de Jorro Durante o Recobrimento de Partículas. Dissertação
(Mestrado em Engenharia Química) Universidade Estadual de Campinas. Campinas, 2003.

AKHNAZAROVA, S.; KAFAROV, V. Experiment optimization in chemistry and chemical engineering. Moscow: Mir, 1982.

BARROS NETO, B.; SCARMINIO, I. S.; BRUNS, R. E. Como fazer experimentos: pesquisa e desenvolvimento na ciência e na indústria. Editora da Unicamp. Campinas, 2001.

BORSARI, F. Fertilizantes inteligentes: As novas tecnologias permitem o consumo dos nutrientespelas plantas de forma gradativa, lenta e controlada. Agro DBO, São Paulo, $\mathrm{N}^{\mathrm{O}}$ 45, jun. 2013. Disponível em: <http://issuu.com/eriklm/docs/ed_agro_45_96 8a961f50d9b8/1?e=5757079/3086374>. Acesso em: 19 abr. 2015.

CANTARELLA, H. Nitrogênio. In: NOVAIS, R. F. Fertilidade do solo. 2. ed. Sociedade Brasileira de Ciencia do Solo, Viçosa, 2007. p.375-470.

DONIDA, M. W. Recobrimento Polimérico da Ureia em Leito de Jorro Bidimensional. Dissertação (Mestrado em Engenharia Química), Universidade Estadual de Campinas, 2000.

DUARTE, D. S. A. Perdas de amônia por volatilização em solo tratado com ureia, na presença de resíduos cultuais. Dissertação (Mestrado em Solos e Nutrição de Plantas) Universidade de São Paulo, Piracicaba, 2007.

MATHUR, K.; EPSTEIN, N. Spouted Beds, 1 .ed. Academic Press Incorporated, New York, 1974.p. 304.

REZENDE, F. A. Recobrimento de grânulos farmacêuticos em leito fluidizado. Dissertação (Mestrado em Ciências 
Farmacêuticas) - Universidade de São Paulo, Ribeirão Preto, 2007.

ROSA, G. S. Recobrimento de Ureia em Leito de Jorro para Minimizar as Perdas de Nitrogênio por Volatilização. Dissertação (Mestrado em Engenharia Química) Universidade Estadual de Campinas. Campinas, 2010.

SILVA, O. S. Desenvolvimento do processo de recobrimento e secagem de microgrânulos em leito fluidizado. Tese (Doutorado em Engenharia Química) Universidade Estadual de Campinas, Campinas, 2003. f. 140.

TUNALA, L. F. Desenvolvimento de equipamento para recobrimento de partículas em leito de jorro fluidizado. Dissertação (Mestrado em Engenharia Química) - Universidade Federal Rural do Rio de Janeiro, Seropédica, 2005.

VITTI, G. C.; REIRINCHS, R. Formas tradicionais e alternativas de obtenção e utilização do nitrogênio e do enxofre: uma visão Holística. In: YAMADA, T.; STIPP, S. R.; VITTI, G. C. Nitrogênio e Enxofre: na agricultura brasileira.IPNI: Piracicaba, 2007. p. $109-157$.

VUOLO, M G. Utilização de fontes de Nitrogênio em Tanzânia (Panicum maximum Jacq.) no final da estação das águas. Dissertação (Mestrado em Agronomia) Universidade do Oeste Paulista, Presidente Prudente, 2006.

\section{AGRADECIMENTOS}

Ao grupo de pesquisa, Engenharia de Processos em Sistemas Particulados da Unipampa, pela construção de novas ideias.

Ao $\mathrm{CNPq}$ e ao Programa de PósGraduação em Engenharia da Unipampa pelo apoio financeiro e oportunidade de realizar o curso de mestrado. A Unipampa pelas bolsas de iniciação científica e de extensão.

\section{TRABALHOS FUTUROS}

Futuramente será realizada a verificação experimental do ponto ótimo, ou seja, avaliar as respostas obtidas nas condições otimizadas, comparando-se com o valor predito pela otimização. Se os valores forem suficientemente próximos, verifica-se a boa qualidade do procedimento escolhido para a otimização. 